\title{
Enhanced Electroplasticity through Room-Temperature Dynamic Recrystallization in a Mg-3Al-1Sn-1Zn Alloy
}

\author{
Hong Xu ${ }^{1,2}$, Yu-Jie Zou ${ }^{1}$, Yu Huang ${ }^{1}$, Pin-Kui Ma ${ }^{1, *}$, Zhi-Peng Guo ${ }^{1}$, You Zhou ${ }^{1}$ and Yu-Peng Wang ${ }^{1}$ \\ 1 State Key Laboratory of Automotive Simulation and Control, Nanling Campus, Jilin University, \\ No. 5988 Renmin Street, Changchun 130025, China; xh@jlu.edu.cn (H.X.); zouyj18@mails.jlu.edu.cn (Y.-J.Z.); \\ huangyu17@mails.jlu.edu.cn (Y.H.); guozp18@mails.jlu.edu.cn (Z.-P.G.); zhouyou17@mails.jlu.edu.cn (Y.Z.); \\ yupeng20@mails.jlu.edu.cn (Y.-P.W.) \\ 2 Key Laboratory of Automobile Materials of Ministry of Education, School of Materials Science and \\ Engineering, Nanling Campus, Jilin University, No. 5988 Renmin Street, Changchun 130025, China \\ * Correspondence: mapk@jlu.edu.cn; Tel./Fax: +86-135-0443-9451
}

Citation: Xu, H.; Zou, Y.-J.; Huang,

Y.; Ma, P.-K.; Guo, Z.-P.; Zhou, Y.;

Wang, Y.-P. Enhanced Electroplasticity through Room-Temperature Dynamic Recrystallization in a Mg-3Al-1Sn-1Zn Alloy. Materials 2021, 14, 3739. https://doi.org/10.3390/ma14133739

Academic Editor: Adam Grajcar

Received: 16 May 2021

Accepted: 29 June 2021

Published: 3 July 2021

Publisher's Note: MDPI stays neutral with regard to jurisdictional claims in published maps and institutional affiliations.

Copyright: (c) 2021 by the authors. Licensee MDPI, Basel, Switzerland. This article is an open access article distributed under the terms and conditions of the Creative Commons Attribution (CC BY) license (https:/ / creativecommons.org/licenses/by/ $4.0 /)$.

\begin{abstract}
It has been well known that electric pulse can be utilized to enhance the plasticity of metals, which is attributed to the change of dislocation dynamics, e.g., localized planar slip to homogeneous wavy slip. Here, we show another effect of pulse current, which facilitates texture weakening through room-temperature dynamic recrystallization and additionally improve the plasticity of a polycrystalline Mg-3Al-1Sn-1Zn alloy. By conducting a tensile test under electrical pulse, we found that the peak flow stress and fracture strain depend strongly on current density. As peak current densities increases, the flow stress drops and the fracture strain increases. Our Electron Backscatter Diffraction results suggest that dynamic recrystallization occurs at room temperature, which develops a weakened texture. Our work provides a new insight into electroplasticity mechanism in $\mathrm{Mg}$ alloys.
\end{abstract}

Keywords: magnesium alloys; pulsed current; recrystallization; texture

\section{Introduction}

Wrought magnesium alloys attract increasing attentions in lightweight structural applications because of their low density, high specific strength and stiffness, and good damping capacity [1-3]. However, the poor room-temperature ductility hinders the secondary processing, such as drawing and bending, thus, limiting their applications [4,5]. The electrically assisted manufacturing is a promising technology because the plasticity of metallic materials can be significantly enhanced by pulsed current during deformation. Meanwhile, the energy consumption due to pulsed current is usually lesser than that of heating material to a temperature that affords the same fracture strain, so that electrically assisted manufacturing is economically attractive [6]. As a consequence, this technology has been successfully applied to improve the formability of numerous metallic materials, i.e., aluminum alloys, magnesium alloys, titanium alloys, zirconium alloys, and steels [4-9].

However, the physical origin of electroplasticity is still not clear in the literature, due to the variety of different metallic materials. For example, Zhao et al. [10] recently reported the electroplasticity in a Ti-Al alloy originates from defect reconfiguration such as the transition of dislocation substructure from planner slip to wavy slip due to electropulsing. However, more significantly, the imposition of a pulsed current may lead to obvious microstructure modifications such as recrystallization, ageing, dissolution, and microstructure healing [10-12]. Jiang et al. [13] and Guan et al. [14] achieved enhanced high-temperature recrystallization in both cold-rolled AZ91 and AZ31 after subjected electropulsing treatment. Moreover, Conrad et al. [15] found that the pulsed current increased the recrystallization nucleation rate of the cold-worked copper. It has been proposed that the thermal effect caused by Joule heating of electropulsing treatment is mostly responsible for the enhanced recrystallization during deformation. In contrast, Park et al. [16] 
reported that recrystallization can occur at a lower temperature of $100{ }^{\circ} \mathrm{C}$ by electropulsing treatment, while it is difficult by traditional heat treatment in a furnace under the same temperature. Therefore, enhancing recrystallization by electropulsing treatment is not only a thermal response, but an athermal response is important. The above studies suggest strongly a correlation between recrystallization and electroplasticity. However, the effects of electric current on possible room-temperature recrystallization are still unclear in the literature. In particular, dynamical recrystallization mechanisms (DXR) during deformation assisted by pulse current has yet been well recognized.

In this work, electropulsing with different current densities was imposed to an $\mathrm{Mg}-3$ Al-1 Sn-1 Zn (ATZ311) alloy during uniaxial tension at room temperature. The microstructure evolution and the recrystallization mechanism of ATZ311 alloy during electropulsing treatment were investigated in detail based on EBSD analysis. We show that dynamic recrystallization under pulsed current not only lowers the flow stress and accelerates recrystallization, but also refines grain and weakens texture. This work may provide a new insight to understand the dynamic recrystallization assisted by electropulsing in magnesium alloy.

\section{Experimental Procedures}

The extruded Mg-3 Al-1 Sn-1 Zn (wt. \%), denoted as ATZ311 in this work, a sheet with a thickness of $1.2 \mathrm{~mm}$ was selected as raw material. Subsequently, the sheet was annealed at $200{ }^{\circ} \mathrm{C}$ for $1 \mathrm{~h}$ to relieve the residual stress, which acts as the initial alloy. The initial alloy has a near-equiaxed grain structure with an average grain size of $\sim 43 \mu \mathrm{m}$ (Figure 1 ).



Figure 1. Optical microstructure of the initial alloy.

The uniaxial tensile experiment under pulse current along extruded direction (ED) is performed on a WDW-200 tensile machine (CCKX, Changchun, China), with an initial strain rate of $10^{-3} \mathrm{~s}^{-1}$. Figure 2 a shows the tensile specimen size, with a thickness of $1.2 \mathrm{~mm}$. The pulsed current was generated by a 4000 FN DC power supply (CHANT, Zibo, China). The current parameters are shown in Table 1. Figure 2a shows the schematic diagram of electropulsing treatment assisted tension device where the pulse power is connected with the grips by wire. The grips and the tensile machine are separated by insulating wood and mica to ensure the insulation. Meanwhile, temperature variations of the sample during tension were recorded by FILR-A300 infrared thermal imager (FILR, Stockholm, Sweden) during the tensile test. Microstructure characterizations were carried out on the JEOL JSM-7001F field emission scanning electron microscope equipped (Jeol, Japan) with the electron backscattered diffraction (EBSD) analysis system. The EBSD microscope voltage and current are set as $20 \mathrm{~V}$ and 140-150 $\mu \mathrm{A}$. We use CHANNEL5 software to process EBSD data. The samples for EBSD were prepared by electro polishing with an AC2 solution at $20 \mathrm{~V}$ for $60-120 \mathrm{~s}$ at $-30^{\circ} \mathrm{C}$. The devices used for electropolishing 
are RXN-305D constant-voltage DC power supply (ZHAOXIN, Shenzhen, China) and HJ-3 temperature-controlled magnetic mixer (XUSHEN, Changzhou, China).
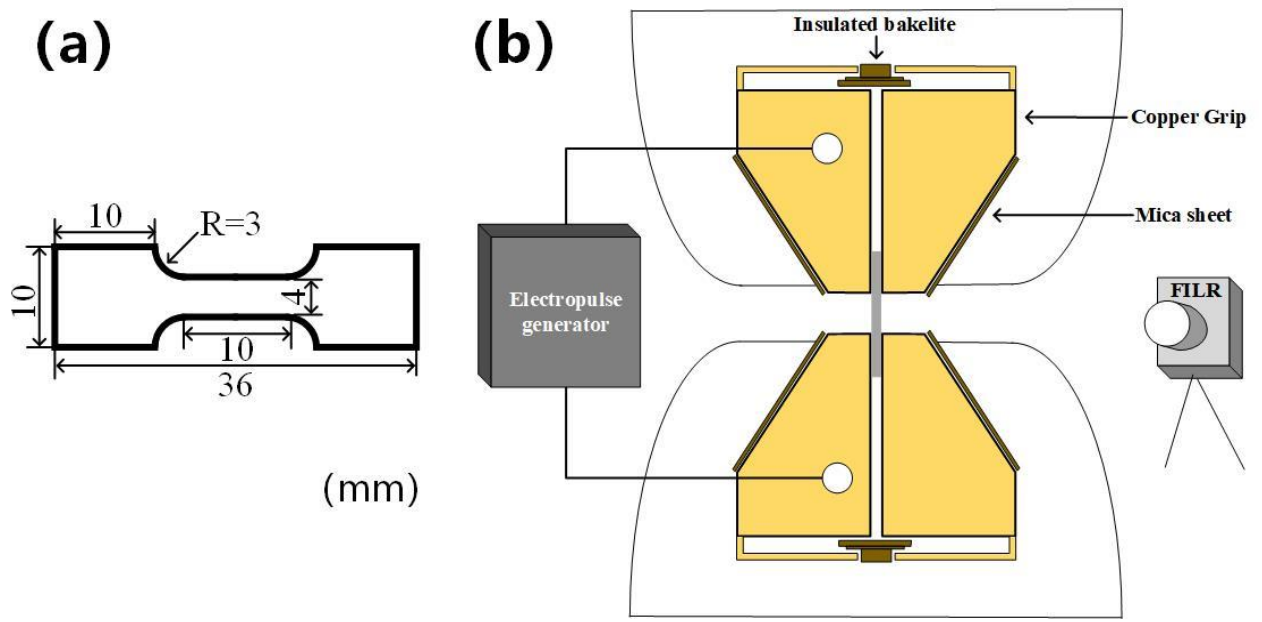

Figure 2. (a) Tensile specimen size; (b) schematic diagram of the electropulsed treatment assisted tension device.

Table 1. The current parameters.

\begin{tabular}{ccccc}
\hline & Voltage & Periodicity & Duration & JP \\
\hline 1 & $12 \mathrm{~V}$ & $2000 \mu \mathrm{s}$ & $500 \mu \mathrm{s}$ & $20 \mathrm{~A} / \mathrm{mm}^{2}$ \\
2 & $12 \mathrm{~V}$ & $2000 \mu \mathrm{s}$ & $500 \mu \mathrm{s}$ & $30 \mathrm{~A} / \mathrm{mm}^{2}$ \\
\hline
\end{tabular}

\section{Results and Discussion}

\subsection{Mechanical Behavior during Tensile Test under Pulse Current}

Figure 3a shows the typical engineering stress-strain curves under different peak current densities $\left(\mathrm{J}_{\mathrm{P}}\right)$. It is clear that the flow stress drops but the fracture strain increases with an increase of $\mathrm{J}_{\mathrm{P}}$, which is in complete agreement with the case of other metallic systems under pulse current $[10,11,13]$. The temperature change during tension was recorded by an infrared thermal imager, as shown in Figure $3 b$. The initial temperatures are $\sim 30^{\circ} \mathrm{C}$ and $\sim 80^{\circ} \mathrm{C}$ under 20 and $30 \mathrm{~A} / \mathrm{mm}^{2}$, respectively, which indicates that increased peak current densities lead to upward initial temperatures. Specifically, under $20 \mathrm{~A} / \mathrm{mm}^{2}$, the temperature change with increasing strain is very small, with a maximum temperature of only $41^{\circ} \mathrm{C}$, close to room temperature. Under $30 \mathrm{~A} / \mathrm{mm}^{2}$, the temperature remains near constant before the strain of $\sim 24 \%$, but the temperature gradually increases until failure, with a maximum temperature of $\sim 239^{\circ} \mathrm{C}$.

(a)

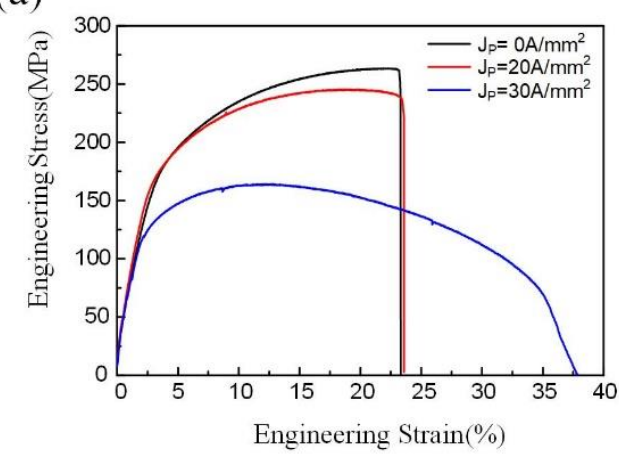

(b)

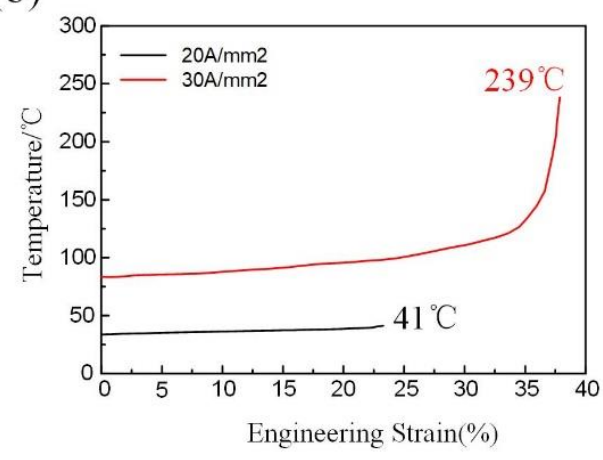

Figure 3. (a) Typical stress-strain curves; (b) temperature variations with strain curves under different peak current densities $\left(J_{P}\right)$. 


\subsection{Microstructure Evolution and Dynamic Recrystallization Behavior during Pulse Current} Tensile Test

At a strain of $8 \%$, the material reaches ultimate tensile strength at $30 \mathrm{~A} / \mathrm{mm}^{2}$. When the strain is $24 \%$, the material has fractured at $20 \mathrm{~A} / \mathrm{mm}^{2}$, while necking occurs at $30 \mathrm{~A} / \mathrm{mm}^{2}$. So, the tensile tests are interrupted at a strain of $8 \%$ and $24 \%$ to investigate microstructure evolution in this work.

Figure 4 shows EBSD analysis results of $8 \%$ and $24 \%$ and under $20 \mathrm{~A} / \mathrm{mm}^{2}$. As noted earlier, this current density almost did not produce high temperature. Accordingly, this tensile deformation can be regarded as room temperature. As it is well known, both basal slip and $\{10-12\}$ twinning is firstly activated during deformation. On the whole, from Figure 4, the deformed microstructure is analogous to the initial microstructure although some large parent grains are lightly elongated along the tensile direction. No obvious recrystallized structures are found. The significant deformation microstructure is characterized by several of $\{10-12\}$ twins at $8 \%$, but it just vanishes at $24 \%$. This phenomenon is so-called to be detwinning [17].

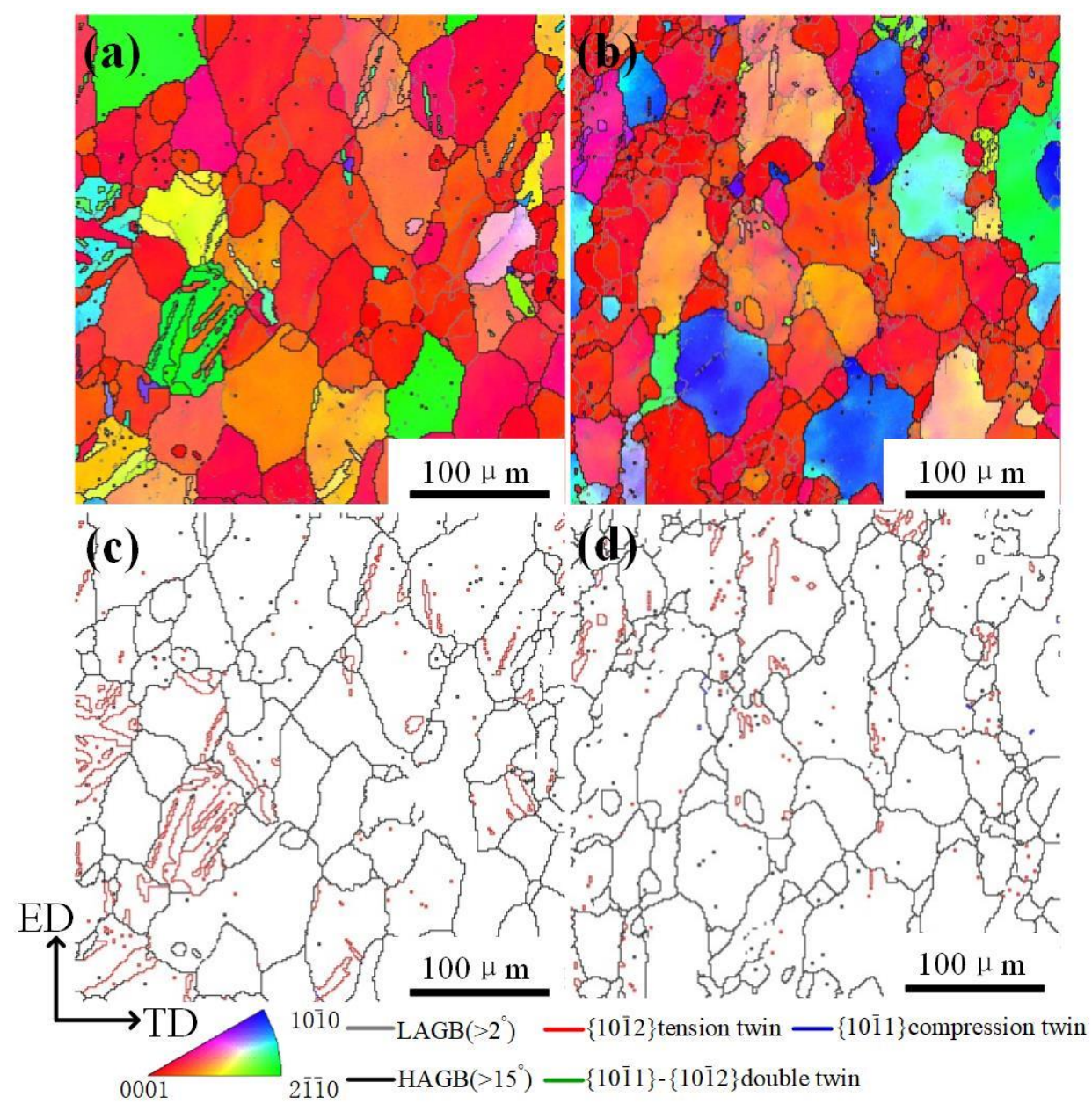

Figure 4. (a,b) IPF images and (c,d) twin distribution of $(\mathbf{a}, \mathbf{c}) 8 \%$ strain and $(\mathbf{b}, \mathbf{d}) 24 \%$ strain under $20 \mathrm{~A} / \mathrm{mm}^{2}$.

At the initial stage, the formation of twins can hinder the dislocation slip because the twin boundary originating from the crystal reorientation between the twinned zones and surrounding zone within grain can effectively hinder dislocation slips, thereby resulting in a strong dislocation pile-up at the twin boundary $[18,19]$. As further straining, the slipped dislocation could across the twin boundary and penetrate into the entire twin. Meanwhile, 
here occur dislocation dissociation reactions from a perfect dislocation dissociating into a partial dislocation and a twinning dislocation.

Such a process offers a possibility for the nucleation of multiple twinning dislocations owing to the interaction of slipped dislocation with the twin boundary [20]. An avalancheslip of multiple twinning dislocations will give rise to the reorientation of twins and the annihilation of twin boundaries. In reality, dislocation across the twin boundary needs to overcome a larger energy barrier. There is a hypothesis of electron wind force that the direct momentum transfers from the electron current to dislocations, which accelerates dislocation slip $[10,11]$. Consequently, the electron wind force effects might enhance the momentum of glide dislocations and promote dislocation across the twin boundary, possibly associating with the detwinning. The occurrence of such a detwinning would slow down strain hardening due to a decreasing overall resistance of twins to the dislocations slip after the vanishing of twins, as shown in Figure 3a.

Figure 5 shows EBSD analysis results of $8 \%$ and $24 \%$ strain under $30 \mathrm{~A} / \mathrm{mm}^{2}$. In the initial sample, there are a few $\{10-12\}$ twins in the parent grains and still no recrystallized structure (Figure $5 \mathrm{a}, \mathrm{c}$ ), although the initial temperature over $80^{\circ} \mathrm{C}$, which seems to be similar to the case of $20 \mathrm{~A} / \mathrm{mm}^{2}$. However, when the strain reached $24 \%$, coarse parent grains are distinctly fined and amounts of low angle grain boundaries (LAGBs) existed within the parent grains. This indicates the occurrence of dynamic recrystallization (DRX) in this strain.



Figure 5. (a,b) IPF images and $(\mathbf{c}, \mathbf{d})$ twin distribution of $(\mathbf{a}, \mathbf{c})$ the initial sample and $(\mathbf{b}, \mathbf{d})$ the final sample under $30 \mathrm{~A} / \mathrm{mm}^{2}$.

From Figure $3 \mathrm{~b}$, we can find that the temperature still decreases $100^{\circ} \mathrm{C}$ at a strain of $24 \%$ under $30 \mathrm{~A} / \mathrm{mm}^{2}$. At $100^{\circ} \mathrm{C}$, it is not enough to drive the occurrence of DRX, implying that electrical effect can significantly promote DRX, besides the thermal effects of the pulse 
current. Note that the DRX degree in different parent grains is different possibly due to orientation discrepancy [21].

According to an investigation on the influence of initial texture on the dynamic recrystallization in AZ31 alloy, it was shown that DRX takes place preferentially in those of grains favorable to the dislocation slips [22]. In addition, the straight twin boundaries in the initial stage have vanished, which suggests that twin boundaries can act as nucleation sites of DRX grains by constantly absorbing dislocations during the deformation process. The twin boundaries similar to high angle grain boundary can hinder the dislocation glide during the plastic deformation, and then dislocations pile-up at twin boundaries will rearrange themselves into dislocation wall or low angle grain boundaries to release energy, and this process leads to new DRXed grains formed in twin boundaries [23].

We counted the misorientation distribution for more than 60 grains in Figure 5d. Representative area A and B are selected for illustration. Figure 6 shows the area A and $B$ in Figure 5. The "point-point" is the misorientation of the data point with respect to the previous data point, and "point-origin" is the misorientation of the data point with respect to the starting point. It can be seen from Figure 6 that there is a large misorientation within the DRX grain, which can indicate that this LAGB must be caused through the lattice rotation due to basal slip within the DRX grains. Consequently, continuous DRX occurred within parent grains. As it is known, continuous DRX occurs by the crossslip of $<$ a $>$ screw dislocations from basal plane to non-basal planes. According to the Friedel-Escaig mechanism [24], <a> screw can convert into an edge dislocation during cross-slip process [25]. Note that $<a>$ screw dislocations can climb, thus abundant LAGB in parent grains could be as a result of dislocation rearrangements by cross-slip and climb. Zhao et al. [10] reported that pulse current can enhance cross-slip. Thus, more non-basal $<a>$ dislocations could be activated and accumulated at LAGB. The LAGBs, which continuously absorb dislocations, can result in CDRX.

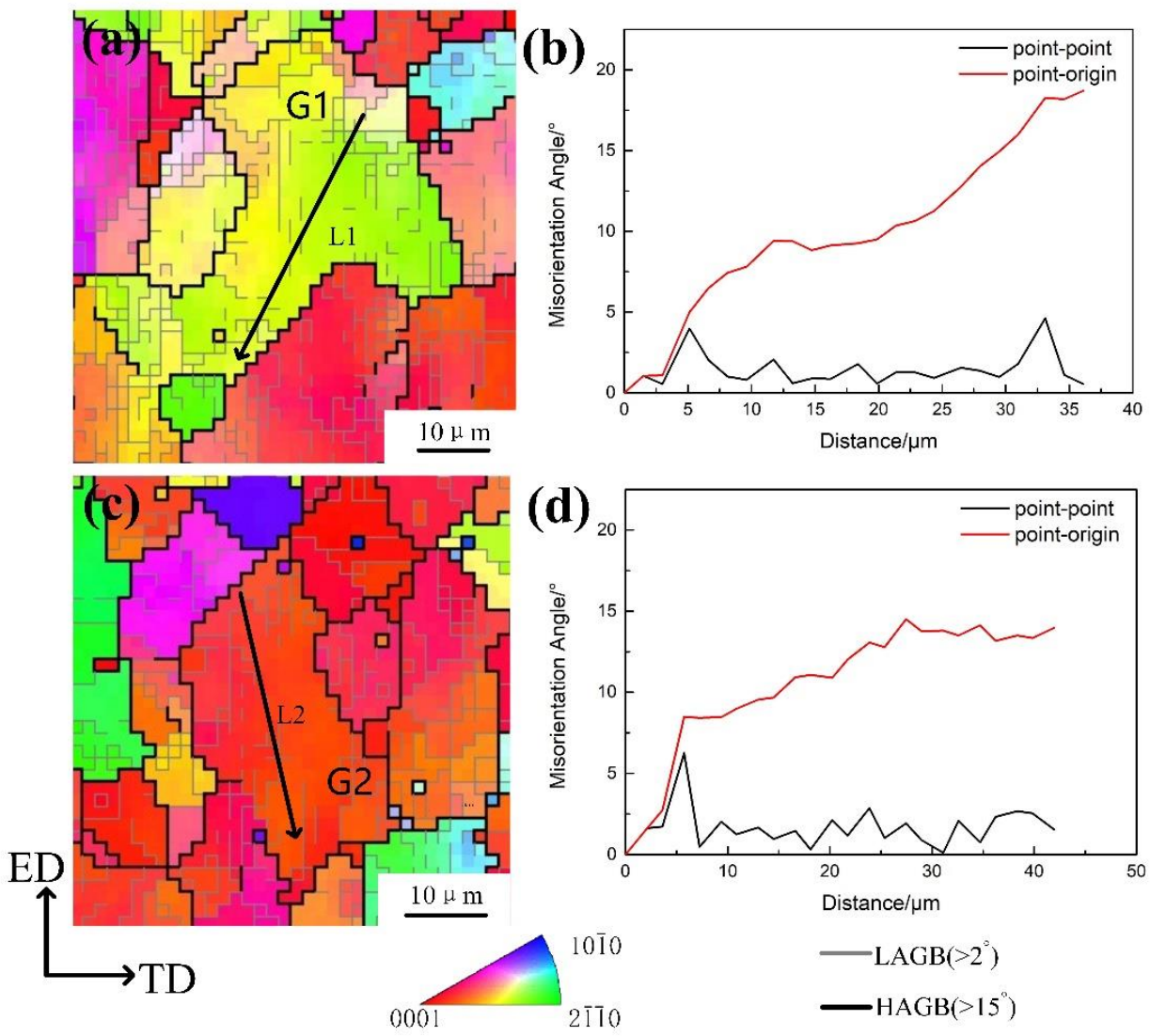

Figure 6. (a,c) the enlarged views of region A and region B in Figure 5b, (b,d) the misorientation distribution along L1 and L2, respectively. 


\subsection{Texture Evolution during Pulse Current Tensile Test}

Figure 7 gives the (0001) pole figure and inverse pole figures of the initial sample and deformed samples with different strains under different peak current densities. Since the initial sample is from an extruded sheet, thus, it exhibits a triple basal texture: strong ND/ / (0001) called ND component, second TD//(0001) called TD component, and weak $\mathrm{ED} / /(0001)$ called ED component via the careful analysis of (0001) pole figure and ND inverse pole figure. However, it should be noted that the intensity of ND component is higher than that of TD component. Additionally, $\{11-20\}$ of majority grains is parallel to ED. With the strain increased to $8 \%$, TD component weakens but ND component strengthens, and $\{11-20\}$ transform into $\{10-10\}$ being parallel to ED for both conditions, especially for case of $30 \mathrm{~A} / \mathrm{mm}^{2}$.



Figure 7. The (0001) pole figures and inverse pole figures of initial sample and deformed samples with different strains under different peak current densities showing texture evolution.

During tension, those grains with ED component are in a favorable orientation for $\{10-12\}$ twinning (see in Figures $4 a$ and $5 a$ ) due to basal planes perpendicular to the ED. $\{10-12\}$ twinning will lead to the $86^{\circ}$ lattice reorientation, namely $c$-axis rotates from being parallel to the ED to ND, which strengthens ND component. The start of tension deformation is accompanied by basal <a> slip, even for those grains with low Schmid factor of basal slips [26]. For the grains with ND and TD components, there is low activation energy of twinning and basal <a> slip, thus non-basal <a> slip will be activated after yielding [26]. Consequently, $\{11-20\}$ transform into $\{10-10\}$ being parallel to ED, which can be attributed to the continuous non-basal <a $>$ slip $[27,28]$.

With further strain to $24 \%$, the texture intensity decreases in both conditions. Under $20 \mathrm{~A} / \mathrm{mm}^{2}$, the reduction of the texture intensity can be attributed to detwinning because of no recrystallization in this case. Under, $30 \mathrm{~A} / \mathrm{mm}^{2}$, apparent recrystallization occurred, which gives rise to an obvious decrease of the texture intensity. As mentioned earlier, twin boundaries provide nucleation sites, promoting DRX. It must be pointed out that further DRX at twin boundaries should weaken the twin texture caused by $\{10-12\}$ twinning [29]. Meanwhile, the faster continued DRX process in the untwinned Mg matrix could result in the development of random texture, weakening the initial texture [30]. 


\section{Conclusions}

In this work, we systematically investigated the microstructure evolution of Mg-3Al$1 \mathrm{Zn}-1 \mathrm{Sn}$ alloy during uniaxial tension under pulsed current, during a room temperature dynamic recrystallization process. Our results show that the flow stress drops but the fracture strain increases with an increase of peak current densities. In the strain of $\sim 8 \%$, $\{10-12\}$ twins are observed at both conditions, but no DRX. Due to $\{10-12\}$ twins and non-basal slips, basal texture are strengthened and $\{11-20\}$ is transformed into $\{10-10\}$ being parallel to ED. Further strain to $\sim 24 \%$, detwinning occurred under $20 \mathrm{~A} / \mathrm{mm}^{2}$, which could be attributed to gliding dislocations across twin boundaries under electron wind force, while significant DRX formed under $30 \mathrm{~A} / \mathrm{mm}^{2}$. We proposed that electrical effect can significantly promote DRX except for the thermal effects of the pulse current because pulsed current only causes a low temperature of $\sim 100{ }^{\circ} \mathrm{C}$ that is difficult to promote DRX. In this case, further DRX at twin boundaries and continue DRX should develop random texture, therefore, weakening initial texture. By investigating the room temperature dynamic recrystallization, our work may provide a new insight into electroplasticity mechanism in Mg alloys.

Author Contributions: Each author equally contributed to the paper. Conceptualization, H.X., Y.-J.Z. and P.-K.M.; data curation, Y.-J.Z., Z.-P.G. and Y.-P.W.; formal analysis, H.X., Z.-P.G. and Y.J.Z.; funding acquisition, H.X. and P.-K.M.; investigation, Y.-J.Z., Y.Z., Y.H., Z.-P.G. and Y.-P.W.; methodology, H.X., Y.-J.Z. and P.-K.M.; project administration, H.X. and P.-K.M.; resources, Y.-P.W. and Z.-P.G.; software, Y.-J.Z., Y.H. and Z.-P.G.; supervision, H.X. and P.-K.M.; validation, Y.-J.Z., Z.-P.G. and Y.-P.W.; visualization, Y.-J.Z., Z.-P.G. and Y.-P.W.; writing-original draft preparation, Y.J.Z., Y.H. and Y.Z.; writing—review and editing, H.X., Y.-J.Z. and P.-K.M. All authors have read and agreed to the published version of the manuscript.

Funding: This research was funded by the Science and Technology Development Program of Jilin Province grant number (No. 20190302060GX).

Conflicts of Interest: The authors declare no conflict of interest.

$\begin{array}{ll}\text { Abbreviations } \\ \text { Abbreviation } & \text { Meaning } \\ \text { ATZ311 } & \text { Mg-3Al-1Sn-1Zn } \\ \text { EDSD } & \text { electron backscattered diffraction } \\ \text { DRX } & \text { dynamical recrystallization mechanisms } \\ \text { CDRX } & \text { continue dynamical recrystallization mechanisms } \\ \text { ED } & \text { extruded direction } \\ \text { TD } & \text { transverse direction } \\ \text { ND } & \text { normal direction } \\ \text { JP } & \text { peak current densities } \\ \text { LAGB } & \text { low angle grain boundary } \\ \text { HAGB } & \text { high angle grain boundary }\end{array}$

\section{References}

1. Hono, K.; Mendis, C.L.; Sasaki, T.T.; Oh-ishi, K. Towards the development of heat-treatable high-strength wrought Mg alloys. Scripta Mater. 2010, 63, 710-715. [CrossRef]

2. Zhang, D.D.; Yang, Q.; Guan, K.; Li, B.S.; Wang, N.; Qin, P.F.; Jiang, B.; Sun, C.; Qin, X.; Tian, Z.; et al. A high-strength low-rare-earth-alloyed magnesium alloy via traditional hot-extrusion. J. Alloys Compd. 2019, 810, 151967. [CrossRef]

3. Wang, Y.; Choo, H. Influence of texture on Hall-Petch relationships in an Mg alloy. Acta Mater. 2014, 81, 83-97. [CrossRef]

4. Li, C.; Zhang, K.F.; Jiang, S.S.; Zhao, J.P. Pulse current auxiliary bulging and deformation mechanism of AZ31 magnesium alloy. Mater. Des. 2010, 34, 170-178. [CrossRef]

5. Xu, Z.H.; Tang, G.Y.; Tian, S.Q.; Ding, F.; Tian, H.Y. Research of electroplastic rolling of AZ31 Mg alloy strip. J. Mater. Process. Technol. 2007, 182, 128-133. [CrossRef]

6. Xiang, S.Q.; Zhang, X.F. Dislocation structure evolution under electroplastic effect. Mater. Sci. Eng. A 2019, 761, 138026. [CrossRef]

7. Li, W.; Shen, Y.; Liu, H.T.; Wang, Y.; Zhu, W.J.; Xie, C.Y. Non-octahedral-like dislocation glides in aluminum induced by athermal efect of electric pulse. J. Mater. Res. 2016, 31, 1193-1200. [CrossRef] 
8. $\quad$ Sheng, Y.Y.; Hua, Y.L.; Wang, X.J.; Zhao, X.Y.; Chen, L.X.; Zhou, H.Y.; Wang, J.; Berndt, C.; Wei, L. Application of high-density electropulsing to improve the performance of metallic materials: Mechanisms, microstructure and properties. Materials 2018, 11, 185. [CrossRef]

9. Islam, Z.; Wang, B.M.; Haque, A. Current density effects on the microstructure of zirconium thin films. Scripta Mater. 2018, 144, 18-21. [CrossRef]

10. Zhao, S.T.; Zhang, R.P.; Chong, Y.; Li, X.Q.; Abu-Odeh, A.; Rothchild, E.; Chrzan, D.C.; Asta, M.; Morris, J.W.M.; Minor, A.M. Defect reconfiguration in a Ti-Al alloy via electroplasticity. Nat. Mater. 2021, 20, 468-472. [CrossRef]

11. Kim, M.J.; Yoon, S.; Park, S.; Jeong, H.J.; Park, J.W.; Kim, K.; Jo, J.; Heo, T.; Hong, S.T.; Cho, S.H.; et al. Elucidating the origin of electroplasticity in metallic materials. Applied Mater. Today 2010, 21, 100874.

12. Xiao, S.H.; Guo, J.D.; Wu, S.D.; He, G.H.; Li, S.X. Recrystallization in fatigued copper single crystals under electropulsing. Scripta Mater. 2002, 46, 1-6. [CrossRef]

13. Jiang, Y.B.; Tang, G.Y.; Shek, C.H.; Liu, W. Microstructure and texture evolution of the cold-rolled AZ91 magnesium alloy strip under electropulsing treatment. J. Alloys Compd. 2011, 509, 4308-4313. [CrossRef]

14. Guan, L.; Tang, G.Y.; Jiang, Y.B.; Chu, P.K. Texture evolution in cold-rolled AZ31 magnesium alloy during electropulsing treatment. J. Alloys Compd. 2009, 487, 309-313. [CrossRef]

15. Conrad, H.; Karam, N.; Mannan, S. Effect of prior cold work on the influence of electric current pulses on the recrystallization of copper. Scripta Mater. 1984, 18, 275-280. [CrossRef]

16. Park, J.-W.; Jeong, H.-J.; Jin, S.-W.; Kim, M.-J.; Lee, K.; Kim, J.J.; Hong, S.-T.; Han, H.N. Effect of electric current on recrystallization kinetics in interstitial free steel and AZ31 magnesium alloy. Mater. Charact. 2017, 133, 70-76. [CrossRef]

17. Sarker, D.; Chen, D.L. Detwinning and strain hardening of an extruded magnesium alloy during compression. Scripta Mater. 2010, 67, 165-168. [CrossRef]

18. Khosravani, A.; Fullwood, D.T.; Adams, B.L.; Rampton, T.M.; Miles, M.P.; Mishra, R.K. Nucleation and propagation of \{10-12\} twins in AZ31 magnesium alloy. Acta Mater. 2015, 100, 202-214. [CrossRef]

19. Koike, J. Enhanced deformation mechanisms by anisotropic plasticity in polycrystalline Mg alloys at room temperature. Metal. Mater. Trans. A 2005, 36A, 1689-1696. [CrossRef]

20. Salem, A.A.; Kalidindi, S.R.; Doherty, R.D. Strain hardening of titanium: Role of deformation twinning. Acta Mater. 2003, 51, 4225-4237. [CrossRef]

21. Mackenzie, L.W.F.; Pekguleryuz, M.O. The recrystallization and texture of magnesium-zinc-cerium alloys. Scripta Mater. 2008, 59, 665-668. [CrossRef]

22. Wang, M.Y.; Xin, R.L.; Wang, B.S.; Liu, Q. Effect of initial texture on dynamic recrystallization of AZ31 Mg alloy during hot rolling. Mater. Sci. Eng. A 2001, 528, 2941-2951. [CrossRef]

23. Chao, H.Y.; Sun, H.F.; Chen, W.Z.; Wang, E.D. Static recrystallization kinetics of a heavily cold drawn AZ31 magnesium alloy under annealing treatment. Mater. Charact. 2001, 62, 312-320. [CrossRef]

24. Couret, A.; Caillard, D. An in situ study of prismatic glide in magnesium-II. Microscopic activation parameters. Acta Metall. 1985, 33, 1447-1454. [CrossRef]

25. Püschl, W.; Schoeck, G.; Kirchner, H.O.K. The line tension of dislocations in anisotropic media. Philos. Mag. 1987, 56, 553-563. [CrossRef]

26. Koike, J.; Kobayashi, T.; Mukai, T.; Watanabe, H.; Suzuki, M.; Maruyama, K.; Higashi, K. The activity of non-basal slip systems and dynamic recovery at room temperature in fine-grained AZ31B magnesium alloys. Acta Mater. 2003, 51, 2055-2065. [CrossRef]

27. Yi, S.B.; Brokmeier, H.G.; Bolmaro, R.E.; Kainer, K.U.; Lippmann, T. In situ measurements of texture variations during a tensile loading of Mg-alloy AM20 using synchrotron X-ray radiation. Scripta Mater. 2004, 51, 455-460. [CrossRef]

28. Yi, S.B.; Davies, C.H.J.; Brokmeier, H.G.; Bolmaro, R.E.; Kainer, K.U.; Homeyer, J. Deformation and texture evolution in AZ31 magnesium alloy during uniaxial loading. Acta Mater. 2006, 54, 549-562. [CrossRef]

29. Xu, S.W.; Oh-ishi, K.; Kamado, S.; Homma, T. Twins, recrystallization and texture evolution of a Mg-5.99 Zn-1.76 Ca-0.35 Mn (wt.\%) alloy during indirect extrusion process. Scripta Mater. 2011, 65, 875-878. [CrossRef]

30. Oh-ishi, K.; Mendis, C.L.; Homma, T.; Kamado, S.; Ohkubo, T.; Hono, K. Bimodally grained microstructure development during hot extrusion of Mg-2.4 Zn-0.1 Ag-0.1 Ca-0.16 Zr (at.\%) alloys. Acta Mater. 2009, 57, 5593-5604. [CrossRef] 